\title{
O SUFIXO -RANA NO PORTUGUÊS FALADO PELO CABOCLO AMAZONENSE
}

\author{
Orlando AZEVEDO* \\ Felício MARGOTTI**
}

- RESUMO: O artigo aborda a formação de palavras com o sufixo -rana no português falado em seis localidades situadas na região do Médio Solimões no Estado do Amazonas. O corpus para a análise foi retirado das respostas dos informantes ao questionário semântico-lexical da tese de Azevedo ${ }^{1}$, que está em andamento e que trata da variação dialetal na região do Baixo Amazonas e do Médio Solimões. Para os propósitos da pesquisa, nossa fundamentação foi baseada no modelo da morfologia gerativa a fim de que fosse possível a construção de uma regra aplicável às bases que esse sufixo seleciona. Os resultados mostraram a existência de formações neológicas, uma vez que não foram encontradas em obras lexicográficas. Além disso, o sufixo -rana ao selecionar bases substantivas não muda a classe gramatical da palavra primitiva ao formar novos substantivos. Devido à regularidade, foi possível estabelecermos uma regra de formação de palavras para o sufixo -rana no português falado nessa região da Amazônia brasileira.

- PALAVRAS-CHAVE: Lexicologia. Morfologia gerativa. Região amazônica. Sufixo -rana.

\section{Introdução}

Este trabalho surgiu a partir da motivação que tivemos ao constatarmos as ocorrências, no português amazônico, de vocábulos formados com o sufixo de origem indígena -rana, os quais foram encontrados nas respostas do questionário semântico-lexical aplicado nas comunidades e cidades localizadas na região do médio Solimões/AM (respectivamente, Saubinha, Ariri, Itapéua, Costa do Juçara e as cidades Coari e Codajás). Os dados do OSL (questionário semântico-lexical), elaborado e aplicado de acordo com princípios e método da geolinguística

* Doutorando em Linguistica. UFSC - Universidade Federal de Santa Catarina. Centro de Comunicação e Expressão - Pós-Graduação em Linguistica. Florianópolis - Santa Catarina - Brasil. 88040-900 orlandoazevedo@ymail.com

** UFSC - Universidade Federal de Santa Catarina. Centro de Comunicação e Expressão - Departamento de Língua e Literatura Vernácula. Florianópolis - Santa Catarina - Brasil. 88040-900 - wfelicio@cce.ufsc.br

1 AZEVEDO, O. Aspectos dialetais do português do Médio Solimões (AM) e do Baixo Amazonas (PA): um estudo sobre as vogais médias pretônicas e sobre o léxico. Santa Catarina: Florianópolis - UFSC (Tese em andamento). 
pluridimensonal, fazem parte da Tese de Azevedo, em andamento, que trata da variação lexical nesses pontos da região amazônica.

Nosso propósito foi tanto descobrir se as formações de palavras com o sufixo rana se encontravam dicionarizadas, quanto descrever as bases que esse sufixo seleciona. Após termos comparado os dados entre as variantes do português falado amazônico com o português escrito constante nos dicionários Ferreira (2009) e Houaiss et al. (2009) foi possível aplicarmos, segundo a morfologia gerativa, a regra geral de formação de palavra (RFP) para o sufixo -rana, que ocorreu 32 vezes incluindo as formas alternantes em todo corpus mínimo encontrado no QSL. Tanto as formações com o sufixo -rana constatadas no português falado nos 08 pontos de inquérito, quanto a gama de vocábulos registrados nos dicionários com esse mesmo sufixo, enquadram-se no processo de formação de palavras por derivação, com vistas à criação de neologismos relacionados à fauna e à flora regional amazônica.

\section{A formação de palavras por sufixação}

A sufixação e a prefixação correspondem aos processos de formação de palavras em português por derivação, nos quais são observados os parâmetros estabelecidos na língua portuguesa a partir da combinação entre palavras e afixos já existentes no idioma. Na perspectiva da morfologia gerativa, o falante, mesmo sendo iletrado, conhece as regras de formação de palavras, e, por isso, será capaz de criar novas palavras na língua a partir dos recursos linguísticos previstos pela gramática da língua. Tal mecanismo, a título de ilustração, é muito usado pelas crianças como representado neste diálogo entre a mãe e a criança: "-Filha, tá quente o chá! -Então, diquenta!"

Consideramos que as bases mais comuns a que os sufixos, via de regra, se fixam são substantivos, adjetivos e verbos (BASíLIO, 2009), sendo que a maioria dos processos de formação de palavras por sufixação muda a classe gramatical da palavra primitiva, e a produtividade de cada sufixo tem a ver unicamente com o tipo de base (s), que seleciona como, por exemplo, o sufixo $X$-vel forma adjetivos com verbos transitivos diretos: amar + -vel = amável, estimar + -vel = estimável, louvar + -vel = louvável, e rejeita outras bases como o substantivo homem $+-v e l=$ *homemvel e o adjetivo beleza $+-v e l=$ *belezável. Se tivermos a estrutura morfológica de um verbo em $X$-izar, o sufixo correspondente a forma nominalizada será -ção; por outro lado se for $X$-ecer, o sufixo atuante na formação da nova palavra será - mento (BASÍLIO, 2009). Além disso, conforme o contexto de uso, o falante pode priorizar a formação de palavras a partir da escolha das bases e de sufixos existentes na língua. Logo, as condições de produção de cada sufixo tem a ver com o contexto em que é empregado, ou seja, com o ambiente 
discursivo ou cultural que envolve o usuário da língua. (BASÍLIO, 1993). Por exemplo, tomemos as realizações do vocábulo "não" na linguagem informal e na linguagem formal, respectivamente: na linguagem falada informal, o usuário faz as realizações do "não" como "não", " não é", "né" e "nũ" com função adverbial, como partícula enfática para realçar a negação ou para pedir confirmação do interlocutor como em "-Ele foi pra festa? -Nũ foi não, né!"; já na linguagem formal falada ou escrita, com o mesmo vocábulo "não", teremos construções tipo "não-lucrativo", "não-didático", "não-jurídico", "não-escrito" (ALVES, 2002), nas quais o "não" tem a função de servir como prefixo negativo ao selecionar bases adjetivas e formas participiais com função adjetiva. Portanto, os sufixos não selecionam qualquer base, podem mudar ou não a classe gramatical da palavra derivada e são mais produtivos em determinados ambientes discursivos ou culturais, onde há necessidade de nomeação de novos referentes. Baseado nisso, passamos a analisar as particularidades do sufixo -rana, que contribuiu acentuadamente na formação de novas palavras no português do Brasil, na Amazônia.

\section{Formação de palavras com o sufixo -rana}

O sufixo -rana, documentado no século XVI (HOUAISS, 2009), se fixava unicamente a bases tupi, as quais atribuía uma característica qualitativa. Devido à facilidade que tal sufixo possui de selecionar palavras pertencentes à classe dos substantivos, o sufixo -rana possibilitou, assim, uma espécie de contaminação linguística com bases substantivas ao se misturar com raízes de outras línguas como no caso com as da língua portuguesa, que notoriamente recebeu uma grande contribuição de lexias provenientes de línguas indígenas, dentre elas as pertencentes às famílias do tronco tupi.

Consideramos a natureza do morfe -rana ser sufixal, porque desempenha a função de sufixo ao se fixar na parte final do vocábulo e por ter contribuído para a formação de muitas palavras novas, as quais foram incorporadas ao léxico do português do Brasil. No corpus mínimo analisado, as ocorrências do sufixo -rana correspondem a vocábulos cujos referentes estão presentes na região amazônica. Tais vocábulos, identificados através de um questionário semântico-lexical, constituem um rol apenas exemplificativo, e no processo de sufixação obedeceram ao princípio da economia linguística, pois partiram de bases substantivas préexistentes e de vários níveis semânticos. A maioria dos vocábulos formados com o sufixo -rana é muito conhecida nas variedades do português amazônico, e faz parte, principalmente, do repertório linguístico dos pecadores de rios, lagos e igapós. Encontramos no corpus mínimo as seguintes formações apresentadas na tabela 1 abaixo: 
Tabela 1 - Palavras formadas com o sufixo -rana

\begin{tabular}{|c|c|c|c|c|c|}
\hline No. & Base & Sufixo & Sufixação & $\begin{array}{l}\text { Variações } \\
\text { encontradas }\end{array}$ & Etimologia ${ }^{2}$ \\
\hline 01 & Abacaxi & -rana & Abacaxirana & 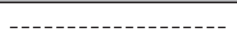 & Tupi = iu9aka'ti \\
\hline 02 & Abacate & -rana & Abacaterana & $\begin{array}{l}\text { Baquitirana, } \\
\text { bacatirana }\end{array}$ & Náuatle $^{3}=$ au9a'katl ${ }^{4}$ \\
\hline 03 & Abio & -rana & Abiorana & $\begin{array}{l}\text { Abiurana, } \\
\text { biorana }\end{array}$ & Tupi= a'u9iu \\
\hline 04 & Cabaça & -rana & Cabaçurana & & $\begin{array}{l}\text { Provavelmente de } \\
\text { origem pré-romana }\end{array}$ \\
\hline 05 & Caju & -rana & Cajurana & 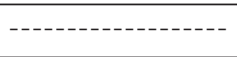 & Tupi= aka'i9u \\
\hline 06 & Cana & -rana & Canarana & -- & $\begin{array}{l}\text { Latim= canna, } \\
\text { derivada do grego } \\
\text { kánna }\end{array}$ \\
\hline 07 & Feijão & -rana & Feijãorana & Fejurana & Latim $=$ faseolus $-i$ \\
\hline 08 & Jacaré & -rana & Jacarerana & 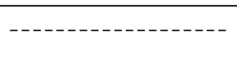 & Tupi=igaka're \\
\hline 09 & Jatuarana & -rana & Jatuarana & Jutuarana & Tupi=iatu ${ }^{5}$ \\
\hline 10 & Limão & -rana & Limãorana & Limorana & $\begin{array}{l}\text { Persa }^{6}=\text { limu ou } \\
\text { laimon }\end{array}$ \\
\hline 11 & Marirana & -rana & Marirana & & $\begin{array}{l}\text { Tupi= umarí ou } \\
\text { umaríiua }\end{array}$ \\
\hline 12 & Melancia & -rana & Melanciarana & - - - - - - - - & De origem incerta \\
\hline 13 & Piquiá & -rana & Piquiarana & - & Tupi= pequi'a \\
\hline 14 & 0 & -rana & Orana & & $\begin{array}{l}\text { Ocorre prótese de "o" } \\
\text { no sufixo -rana }\end{array}$ \\
\hline 15 & Pupunha & -rana & Pupunharana & & $\begin{array}{l}\text { De étimo } \\
\text { indeterminado }\end{array}$ \\
\hline 16 & Oei & -rana & Oerana & & $\begin{array}{l}\text { Provavelmente de } \\
\text { origem tupi. }\end{array}$ \\
\hline
\end{tabular}

2 A etimologia das palavras foi baseada nas definições dos dicionários constantes na referência deste trabalho. Quanto a forma primitiva da palavra, foi retirada do dicionário Etimológico da Língua Portuguesa.

3 Língua indígena extinta, que era falada pelos astecas e pertencente à família linguística auto-asteca da América Central e do México Central e Meridional.

4 O termo au9a'katl sofreu variação para aguacate em espanhol, que por sua vez se transformou em abacate em português.

5 Etimologia dada pelo dicionário tupi-português/português-tupi constante na referência deste trabalho.

6 Definição dada pelo dicionário Aulete digital. Disponível em: <www.aulete.com.br>. Acesso em: 12 jun. 2011. 


\begin{tabular}{|c|c|c|c|c|c|}
\hline No. & Base & Sufixo & Sufixação & $\begin{array}{l}\text { Variações } \\
\text { encontradas }\end{array}$ & Etimologia ${ }^{2}$ \\
\hline 17 & Saboeira & -rana & Saboarana & Saborana & $\begin{array}{l}\text { Provavelmente de } \\
\text { origem Tupi }\end{array}$ \\
\hline 18 & Seringa & -rana & Seringarana & Siringarana & $\begin{array}{l}\text { Latim= syringa, } \\
\text { derivada do grego } \\
\text { syrigx-iggos }\end{array}$ \\
\hline 19 & Tabacu & -rana & Tabacurana & 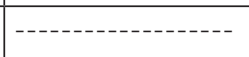 & De base desconhecida \\
\hline 20 & Tupinambá & -rana & Tupinambarana & 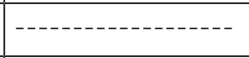 & Tupi = tupinambá \\
\hline 21 & Uixi & -rana & Uixirana & Xirana & $\begin{array}{l}\text { Provavelmente de } \\
\text { origem tupi }\end{array}$ \\
\hline 22 & Urucu & -rana & Urucurana & 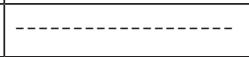 & Tupi = uru'ku \\
\hline
\end{tabular}

Fonte: Questionário semântico-lexical da Tese (em andamento) da autoria de Azevedo.

Das palavras listadas acima, não foram encontradas nos dicionários de língua portuguesa Houaiss (2009) e Ferreira (2009) abacaxirana, cabaçurana, feijãorana, melanciarana, piquiarana, orana, uixirana e as variantes bacatiriana e baquitirana (variantes de abacaterana), oerana (variante de oeirana), saborana (variante de saboarana), siringarana (variante de seringarana), tabacurana (variante de tabacarana, mas com referentes divergentes), xirana (variante de uixirana), limorana (variante de limãorana), jutuarana (variante de jatuarana) e fejurana (variante de feijãorana).

O conteúdo semântico de -rana nas formações acima segundo o Houaiss (2009) e Ferreira (2009) é "semelhante a", "igual a". Dessa forma, temos: abacaxirana, que significa igual ou semelhante ao abacaxi; abacaterana, que significa igual ou semelhante ao abacate; abiurana, que significa igual ou semelhante ao abiu; cabaçurana, que significa igual ou semelhante à cabaça; cajurana, que significa igual ou semelhante ao caju; canarana, que significa igual ou semelhante à cana; feijãorana, que significa igual ou semelhante ao feijão; jacarerana, que significa igual ou semelhante ao jacaré, limãorana, que significa igual ou semelhante ao limão; marirana, que significa igual ou semelhante ao mari (fruta oval comestível na região do médio Solimões); melanciarana, que significa igual ou semelhante à melancia; piquiarana, que significa igual ou semelhante ao pequiá, pupunhara, que significa igual ou semelhante à pupunha; siringarana, que significa igual ao semelhante à seringa; tupinambarana ${ }^{7}$ que significa igual ou semelhante ao tupinambá; uixirana, que significa igual ou semelhante ao uixi (fruta comestível em toda região Amazônica) e; urucurana, que é uma fruta igual ou semelhante

7 Tupinambarana é o nome da ilha onde está situada a cidade de Parintins no Amazonas, portal de entrada para esse Estado. 
ao urucu. Alguns vocábulos, que não são tão comuns, merecem atenção especial como oerana, uma forma variante de oeirana de base "oei" definida da seguinte forma pelo Houaiss (2009):

\section{substantivo feminino \\ Rubrica: angiospermas.}

1arbusto (Alchornea castanaefolia) da fam. das euforbiáceas, nativo do Brasil (AM, BA a MT), de folhas coriáceas, serruladas, espinescentes e peninérveas, flores inconspícuas, em espigas pêndulas e unissexuais, e cápsulas pilosas; uirana

2Regionalismo: Amazonas.

m.q. ${ }^{8}$. 1salgueiro (Salix chilensis)

Na definição da variante oerana feita por uma informante do baixo Amazonas existe a referência a uma árvore com folhas chatas, que cresce às margens do rio Amazonas, e vai ao encontro da definição dada pelo dicionário acima. Por sua vez, o vocábulo saboarana foi classificado como "substantivo feminino, rubrica: angiospermas. Regionalismo: Amazonas. m.q. ${ }^{9}$ saboeirana (HOUAISS, 2009), e na informação dada pelo falante da comunidade Itapéua em resposta ao QSL 152, temos a seguinte descrição:

Rapaz, tem. Tem a invira. Tambaqui come siringa, o matrinxã come a invira, éé... -Essa invira é tipo uma invira mermo? -é uma árvore de pau, que dá invira e dá essas fruta idêntica essa óh! Prêtinha. Aí tem... tem a cajurana também, que o tambaqui come. Tem a saboarana, que o tambaqui come também [...] -Aqui só no logo, a saboarana dá uma fruta assim óh! e a cajura, ela dá agora [...] nessa época [...] saboarana, ela cai tchuum! ela bem azeda! azeda! azeda! Deusu livre! [...] Essa, essa, os cara falaru que ela serve de suco.

Em outra resposta, desta vez de uma informante da comunidade Ariri, são acrescentadas outras características à fruta saboarana:

Tem oo...tem a sabôrãna. -Cumu é a sabôrana? -A sabôrãna, ela é uma castanha, ela é desse tamanho, dessa grussura. Aí quando ela tá madura, ela parte, cai n'água e o tambaqui come. -E a ente come também? -Não! Come,não! é amargo, só o pexe que come.

Quanto ao vocábulo tabacurana, que não foi registrado em nenhum dicionário, tem uma forte saliência com tabacarana, que o Houaiss (2009) classifica como sendo, primeiramente, um substantivo feminino de rubrica angiosperma, mesmo que "fumo-bravo-do-amazonas (Polygonum hispidum) e; em segundo lugar, como

\footnotetext{
8 m. q significa "mesmo que".

9 Mesmo que.
} 
sendo um regionalismo: Minas Gerais, o mesmo que quitoco (Pluchea quitoc). Mas na definição de um dos informantes, tabacurana é uma fruta apreciada pelos peixes dos igapós.

O dicionário Tupi-português/português-tupi (MELLO, 2003) apresenta outra significação para o sufixo -rana: a de "falso", ou seja, para que haja o emprego do sufixo -rana, deve haver um referente original, por exemplo, existe primeira a "cana" da qual é feito o açúcar e a cachaça, depois surge novo vocábulo como "canarana", que pode ser traduzido como "igual a cana", "semelhante à cana" ou "falsa cana", que é um tipo de capim com picos muito comum na beira dos rios e lagos amazônicos, servindo como pastagem para o gado bovino.

As alternantes "feijãorana" e "fejuarana" são respectivamente de dois referentes: o primeiro é explicado pelo informante do baixo Amazonas/PA como sendo um feijão do mato parecido com o feijão verdadeiro, e o segundo é falado pelo informante do médio Solimões como "um mato que cresce nos campo, é um cipó bravo".

O vocábulo "siringarana" (variação de seringarana dada pelos informantes do Médio Solimões) é uma fruta do mato, que possui leite e que serve de alimento, principalmente, para jatuarana.

Assim, acontece com as demais formações como: "melanciarana" sem registro em obras lexicográficas e que foi caracterizada da seguinte forma pela informante da comunidade Saubinha, no médio Solimões:

-Tem a siringa, né! Que o pexe come. -A siringa barriguda ô a siringaí? -Siringaí e a siringa barriguda. Tem aa...essa, cumu é essa fruta aqui? -Pupunharana. -Pupunhara, o marajá, tem o jóuari. (..) e tem a melanciarana, né! Que é uma que cai, o pexe...o pexe gosta de cumê. -Cumu é essa melanciarana? -Ela é merque uma melancia, só que ela é bem jitinha assim, só que ela vévi no igapó. [...]. (QSL152)

Mesmo que os dicionários etimológicos não consigam definir o étimo do vocábulo "melancia", a informante de 52 anos acima, representante da comunidade Saubinha, possui assim como os demais habitantes dessa comunidade, parâmetros de formação de palavras em português internalizados, por essa razão, foi possível a criação de uma palavra nova "melanciarana" cujo referente é uma fruta do igapó parecida com a melancia, mas menor que ela, sendo muito apreciada pelos peixes da região.

Na formação "orana" (ver Tabela 1), que não possui, também, registro em nenhum dicionário da língua portuguesa, o sufixo - rana funciona como verdadeira base, pois não há como saber se o "o" tem carga semântica, por essa razão 
consideramos o "o" como um caso de inserção (prótese) no sufixo -rana, que não tem seu conteúdo esvaziado na formação da nova palavra. A lexia "orana" se refere a uma variedade de peixe parecida com a catrapola, que é o mesmo charuto ou cubil nos diferentes pontos em que o QSL (questionário semânticolexical) foi aplicado. Logo, podemos dizer, de acordo com a variante diatópica, que "orana" é "igual uma catrapola, "igual ao charuto", "igual ao cubil" ou é uma "falsa catrapola", "um falso cubil" e "um falso charuto" se empregarmos o verdadeiro significado desse sufixo.

Outra especialidade do sufixo -rana é a relação híbrida que estabelece com a base selecionada. Por isso, temos formações como "abacaterana", do Náuatle aua'katl mais -rana do tupi; "cabaçurana", do pré-romano cabaça mais -rana do tupi; "canarana", do grego kánna mais -rana do tupi; "feijãorana", do latim faseolus mais -rana do tupi; "limãorana", do persa limon ou laimon mais -rana do tupi. Essa tendência de formações híbridas é encontrada nas palavras que estão dicionarizadas como é o caso de "limãoranazinho" (diminutivo de limãorana), que obedece à hierarquia de formação de palavras no português do Brasil com base + sufixo-rana + sufixo diminutivo (z)inho.

Quanto ao domínio semântico das lexias formadas com o sufixo -rana encontradas no corpus mínimo da tese, temos a seguinte distribuição:

\section{Tabela 2 - Subclasses que o sufixo -rana seleciona}

\begin{tabular}{|c|c|c|c|c|}
\hline Fruta & Peixe & Réptil & Árvore & Toponímia \\
\hline Abacaxirana & Jatuarana & Jacarerana & Oerana & Tupinambarana \\
\hline Abacaterana & Orana & -- & --- & \\
\hline Abiorana & & & & \\
\hline Cabaçurana & -- & --- & -- & \\
\hline Cajurana & & -- & & \\
\hline Canarana & --- & - & -- & \\
\hline Feijãorana & --- & - & - & \\
\hline Limãorana & - & -- & ------- & \\
\hline Marirana & $-\cdots$ & -- & -- & \\
\hline Melanciarana & -------- & - n & -------- & - \\
\hline Piquiarana & -------- & ----------- & -------- & -- \\
\hline Saboarana & -1-- & - - & ------- & -- \\
\hline
\end{tabular}




\begin{tabular}{|c|c|c|c|c|}
\hline Fruta & Peixe & Réptil & Árvore & Toponímia \\
\hline Seringarana & -- & --- & & \\
\hline Tabacurana & $-\cdots$ & ---- & -- & -- \\
\hline Uixirana & -- & $-\cdots$ & -- & \\
\hline Urucurana & - - - & - & -------- & $-\cdots$ \\
\hline Total 16 & 2 & 1 & 1 & 1 \\
\hline
\end{tabular}

Fonte: Questionário semântico-lexical da Tese (em andamento) da autoria de Azevedo.

A maioria dessas formações foi detectada no questionário semânticolexical de no. 152 (QSL152), que solicitava aos informantes a descrição das frutas que os peixes comem na região. Essa característica do sufixo -rana em selecionar bases substantivas pertencentes ao domínio semântico de frutas foi também constatada nos dicionários Ferreira (2009) e Houaiss (2009) como: abacaterana, abiorana, abiurana, acajurana, acapurana, ajurarana, algodãorana, amendoeirana, aperana, araçarana, aricurana, arirana, arumarana, aurana, autuparana, axuarana, batatarana, biorana, biribarana, brancarana, buritirana, caferana, cajarana, cajurana, cambucarana, campinarana, canarana, canharana, canjarana, canjerana, capoeirana, cariperana, cedrorana, coirana, cuirana, cujumarirana, cupuaçurana, curcurana, diambarana, imburana, ingarana, jacarerana, jagoirana, jamburana, jarana, jatuarana, jauarana, jaturana, jenipaparana, jitirana, landirana, laranajarana, limãorana, liomãorana-davárzea, limãoranazinho, maçarana, mandubirana, marrecarana, matarana, marirana, mucurana, muçurana, muquirana, nhamburana, obarana, obaranaçu, obarana-rato, oeirana, oirana, ourana, pacarana, pandarana, pupunhara, quiaborana, quinara, quirana, saboarana, saboeirana, sapucairana, seringarana, Suçuarana, tabacarana, tabarana, tapuirana, tatarana, taturana, taxirana, timborana, timburana, trapiarana, tubarana, uacapurana, ucuquirana, ubarana, uirana, umarirana, umburana, urarirana, uricurana, urucuubarana, urucurana e urutaurana.

A gama de formações com o sufixo -rana acontece com regularidade na seleção de bases substantivas com referentes da flora e da fauna. Com isso, foi possível estabelecermos a seguinte regra de formação de palavras: o sufixo -rana se fixa unicamente a bases substantivas.

A RFP (regra de formação de palavra) no modelo teórico da morfologia gerativa fica representada da seguinte forma:

[X]ar[X]a Y]b (onde " $\mathrm{X}$ " é a base primitiva; O "a" é classe gramatical da base; O "Y" é o afixo que seleciona a base e; o "b" é o produto da junção do afixo com a base 
formando uma nova palavra com mudança de classe gramatical ou formando uma nova palavra sem mudar a classe gramatical).

$[\mathrm{X}] \mathrm{S} \cdot[\mathrm{X}] \mathrm{S}-\mathrm{rana}] \mathrm{S}$

Exemplo 1: [abacaxi]S '[[abacaxi]S -rana]S =[abacaxirana]substantivo

Exemplo 2: [melancia]S·[[melancia]S -rana]S =[melanciarana]substantivo

Exemplo 3: [uixi]S'[[uixi]S -rana]S =[uixirana]substantivo

No exemplo 1 a base substantiva abacaxi mais o sufixo -rana formam novo substantivo abacaxirana;

No exemplo 2 a base substantiva melancia mais o sufixo -rana formam novo substantivo melanciarana;

No exemplo 3 a base substantiva uixi mais o sufixo -rana formam novo substantivo uixirana.

Portanto, o sufixo -rana ao formar novos substantivos, se enquadra entre os sufixos que formam novas palavras sem mudar a classe gramatical. Essas peculiaridades permitem que sejam criadas novas palavras como aquelas que não foram encontradas nos grandes dicionários Houaiss (2009) e Ferreira (2009). Vocábulos como [cupu]S '[cupu]S -rana]S = [cupurana], [urubu]S '[urubu]S -rana] $S=$ [uruburana] são palavras em potencial, que se enquadram dentro da regra de formação de palavra com o sufixo -rana.

\section{Considerações finais}

As formações de palavras com o sufixo -rana acontecem com bases substantivas tanto no português falado amazônico quanto no português escrito, e, principalmente, com palavras que pertencem ao domínio semântico, sobretudo, de frutas e árvores. Como os dados foram coletados por meio do QSL, que não teve o propósito de registrar todas as ocorrências desse sufixo, e também devido à imensidão da região amazônica, cujo léxico é em grande parte de origem indígena, há certamente uma gama maior de palavras a que esse sufixo se junta. Porém, o corpus, apesar de ser limitado, mostra a tendência do sufixo -rana de somente se fixar a bases substantivas, pois tal tendência pode ser verificada até entre as palavras que já estão registradas. A maior parte das lexias com sufixo -rana encontradas nos dicionários são de referentes da região amazônica. Por isso, o ambiente que envolve o homem amazônico favorece o surgimento de léxicos que se referem a elementos da flora e da fauna regional. Entretanto, não podemos dizer, por mais que não se tenha encontrado todas as palavras no português falado amazônico nos dicionários, que o sufixo -rana continua sendo requisitado na formação de novas palavras, pois tais vocábulos que careceram de 
registro, já existiam há décadas, porque são bastante utilizados pelos pescadores e moradores de igapós, rios e lagos amazônicos.

AZEVEDO, O.; MARGOTTI, F. The suffix -rana in the Portuguese spoken by the Amazon "caboclo." Alfa, São Paulo, v.56, n.2, p.611-621, 2012.

- ABSTRACT: This paper aims to analyse the word formation focusing the use of the-rana suffix in the Portuguese spoken in six places located in the region of the Mid Solimões in the State of Amazonas. The corpus for the analysis was taken from the answers given by the informants to a semantic-lexical questionnaire in Azevedo's thesis, which is on development and is about the dialectical variation in the Low Amazonas and Mid Solimões regions. For the purposes of the research, our theorectical foundation was based on the generative morphology model in order to make possible the construction of a rule to be applied to the bases that are selected by this suffix. The results have shown the existence of neological formations, once they had not been found in any lexicographic works. Furthermore, the -rana suffix, when selecting noun bases, does not change the primitive grammatical category to form new nouns. Due to its regularity, it was possible for us to formulate a rule of word formation for the -rana suffix in the Portuguese spoken in that Brazilian Amazonia region.

- KEYWORDS: Lexicology. Generative Morphology. Amazonian region. -rana Suffix.

\section{REFERÊNCIAS}

ALVES, I. M. Formações prefixais no português falado. In: CASTILHO, A. T. (Org.). Gramática do português falado. 3. ed. Campinas: Ed. da UNICAMP, 2002.

AULETE, C. Dicionário Aulete digital. Disponível em: <www.aulete.com.br>. Acesso em: 12 jun. 2011.

AZEVEDO, O. Aspectos dialetais do português do Médio Solimões (AM) e do Baixo Amazonas (PA): um estudo sobre as vogais médias pretônicas e sobre o léxico. Santa Catarina: Florianópolis - UFSC (Tese em andamento).

BASÍLIO, M. Formação e classes de palavras no português do Brasil. 2. ed. São Paulo: Contexto, 2009.

BASÍLIO, M. et al. Derivação, composição e flexão no português falado. In: CASTILHO (Org.). Gramática do português falado. Campinas: Ed. da Unicamp: FAPESP, 1993. v.III.

FERREIRA, A. B. H. Novo dicionário da língua portuguesa. Rio de Janeiro: Nova fronteira, 2009.

HOUAISS, A. et al. Dicionário Houaiss da língua portuguesa. Rio de Janeiro: Objetiva, 2009.

MELLO, O. Dicionário tupi-português/português-tupi. 2. ed. Manaus: EDUA, 2003.

Recebido em 16 de setembro de 2011.

Aprovado em 20 de agosto de 2012. 
